\title{
A HIPÓTESE E A EXPERIÊNCIA CIENTÍFICA EM EDUCAÇÃO EM CIÊNCIA: CONTRIBUTOS PARA UMA REORIENTAÇÃO EPISTEMOLÓGICA
}

\author{
João Praia ${ }^{1}$ \\ António Cachapuz ${ }^{2}$ \\ Daniel Gil-Pérez ${ }^{3}$
}

\begin{abstract}
Resumo: 0 presente artigo desenvolve-se em torno do estatuto epistemológico da hipótese e da expe rimentação, numa perspectiva de transposição para o campo da Educação em Ciência. N ão se trata de olhar aquela vertente pela estrita óptica dos epistemólogos, mas centrar a nossa atenção na busca e apropriação crítica de el ementos fundamentadores de uma teorização para a E ducação em C iência, por sua vez também necessária para orientar práticas educacionais.
\end{abstract}

Unitermos: epistemologia, hipótese, experiência científica, educação em ciência.

Abstract: In this paper we study the epi stemol ogi cal status of hypotheses and experimentation, not for the sake of epistemology but in order to better orient science teacher's education and theirs teaching.

Keywords: epistemology, hypothesis, experimentation, science education.

\section{Introdução}

Este trabal ho situa-se no quadro de um conjunto de três artigos articulados entre si, a serem publicados na revista Educação \& Ciência, e têm em vista discutir problemáticas ligadas à epistemologia do trabalho científico. 0 primeiro "Por uma imagem não deformada do trabalho científico", foi já editado e desenvolveu-se em torno de uma crítica fundamentada às concepções, mais habituais, dos professores sobre tal trabalho, apresentando uma extensa bibliografia capaz de ajudar a melhorar e organizar a sua formação. 0 segundo encontra-se no prelo e refere-se à observação e à teoria científicas, bem como à sua complexa relação, sendo aí focadas incidências para uma adequada atuação do professor em nível das estratégias de ensino. 0 presente artigo, o terceiro, é uma tentativa de resposta às questões e às dificuldades encontradas nas práticas letivas, devido a posições epistemológica marcadamente positivistas, no que diz respeito ao estatuto da hipótese e da experimentação.

$\mathrm{N}$ a unidade enunciada nos três artigos, o que se procura é contribuir para uma viragem na Educação em C iência mais congruente com posições epistemológicas contemporâneas.

\section{A hipótese em ciência}

N uma perspectiva de pendor empirista a hipótese tem um papel apagado e insere se num processo de verificação em que o exame exaustivo dos fatos é determinante para a sua elaboração. No entanto, na perspectiva racional ista contemporânea, que aqui interessa salientar, a hipótese intervem ativamente, desempenhando um importante papel na construção do conhecimento científico.

\footnotetext{
${ }_{1}^{1}$ Professor Associado, Faculdade de Ciências, Universidade do Porto, Portugal (email: jfpraia@fc.up.pt) 2 Professor Catedrático, D epartamento de D idáctica eTecnologia Educativa, U niversidade de Aveiro, Portugal (email: cachapuz@dte.ua.pt)

${ }_{3}^{3}$ Professor C atedrático, D epartamento de D idáctica de lãs Ciências Experimenales, U niversidade deValencia, Espanha. (email: Daniel.gil@uv.es)
} 
Ainda que nos interesse aqui discutir mais o contexto da prova e menos o da descoberta, ou o modo como são geradas, o que se pode aventar é que se trata de um processo complexo que pode ter origem na imaginação fértil, inspiradora, porventura em idéias especulativas, às qual subjaz um fundo reflexivo.

A Enciclopédia Einaudi (1992) diz-nos que "aquilo que hoje em dia, no discurso científico classificamos de hipótese, apenas pode ser considerado como uma paragem provisória do pensamento, seja por conjecturar um facto descrito de modo a ser susceptível de ser estabelecido ou refutado no quadro dos termos que o definem, seja por propor um conceito que justifique provisoriamente a sua coerência e eficácia no raciocínio explicativo dos fenômenos observados ou provocados".

Entretanto, para nós, o que está em causa é, neste momento, a questão da prática científica e de que forma é que ela nos ajuda e dá ensinamentos para o ensino das ciências. Assim, a prática científica pode ser vista como um processo composto de três fases: a criação, val idação e incorporação de conhecimentos, que correspondem à geração de hipóteses, aos testes a que a hipótese(s) é sujeita e ao processo social de aceitação e registro do conhecimento científico (H odson 1988). C ontudo, parece importante fazer a distinção clara entre estas fases no trabalho científico em educação em ciência, pois pode ajudar os alunos a clarificar o propósito e o sentido da própria atividade reflexiva que estão a levar a cabo. Torna-se desejável que haja clarificação entre as duas situações - a criação da hipótese científica e a sua validação - para que possam compreender a complexidade daquela atividade, saber os caminhos que ela envolve e, neste caso, compreender a questão da validade dos testes de confirmação negativa ou de confirmação positiva a que a(s) hipótese(s) está (estão) sujeita(s).

A hipótese tem um papel de articulação e de diálogo entre as teorias, as observações e as experimentações, servindo de guia à própria investigação. Condiciona fortemente os dados a obter num percurso descontínuo, ainda que balizado por um fundo teórico que Ihe dá plausibilidade, intervindo ativamente nas explicações posteriores dos resultados.

U ma vez formulada a hipótese torna-se necessário, em seguida, a sua confirmação. D uas vias são possíveis. A confirmação positiva e a negativa. No entanto, há que ter presente que o processo de confirmação positiva nada nos diz sobre a verdade da hipótese, já que esta pode ser falsa mas confirmada. Porém, uma sistemática e persistente confirmação positiva pode ajudar a tornar o trabalho científico mais apoiado e fazer progredir o programa de investigação a ele associado.

Numa perspectiva do tipo popperiana, como nos refere M askill \& Wallis (1982) tenta-se, através do método hipotético-dedutivo, "aproximar" a ciência dos cientistas da ciência praticada na sala de aula. Assim:

a) o problema é percebido e compreendido como uma descontinuidade em relação a uma teoria explicativa;

b) propõe-se, então, uma outra possível solução que é uma hipótese;

c) e deduzem-se proposições testáveis a partir da hipótese enunciada;

d) que, através de experiências e observações, cuidadosamente seguidas, conduzem a tentativas de falsificação;

e) cuja escolha criteriosa se faz a partir da sua relação, em diálogo, com as teorias. 
Trata-se de uma perspectiva que exige dos al unos grande capacidade criativa, assim como um bom fundo teórico e espírito crítico. Se é certo que o professor tem que providenciar essa excelente formação teórica, incitar a diferença e o pensamento divergente, para levar a descobrir o que não é esperado, não é menos certo que a exigência conceptual a par de processos científicos de elevada complexidade tornam as situações de aula algo difícil. Para se mobilizar tais competências, capacidades e atitudes com eficiência, torna-se necessário conhecer bem o contexto em que se opera e, neste sentido, o domínio dos conteúdos científicos é um requisito fulcral para que tal possa acontecer. As pessoas pensam e lidam de forma mais eficiente nos e com os problemas cujo contexto e conteúdo conhecem melhor, Ihes são particularmente familiares.

0 conhecimento científico é um constante jogo de hipóteses e expectativas lógicas, um constante vaivém entre o que pode ser e o que "é", uma permanente discussão e argumentação/contrargumentação entre a teoria e as observações e as experimentações realizadas. No âmbito desta perspectiva Bady (1979) realizou um estudo sobre a compreensão dos alunos acerca da "lógica da testagem de hipóteses", em diversas escolas com alunos de diferentes anos de escolaridade. 0 autor verificou que poucos al unos pareceram entender a lógica dos testes da hipótese e que menos da metade dos al unos de escolas superiores conseguiram entender que as hipóteses podem ser testadas por tentativas de falsificação. U ma conclusão do estudo, talvez a mais importante, aponta para que "os alunos que acreditam que as hipóteses podem ser testadas e provadas por verificação, parecem ter uma visão simplista e inge nuamente absoluta da natureza das hipóteses científicas e da teoria. D e fato, uma pessoa que não perceba que as hipóteses científicas não podem ser logicamente provadas, mas apenas desaprovadas, não percebe verdadeiramente a natureza da ciência". A irrefutabilidade deixa de ser um sinal, como tantas vezes é percebido pelos professores, de superioridade e, segundo esta perspectiva, reside aqui o carácter dinâmico, a possibilidade do conhecimento científico se desenvolver.

Um outro elemento que será necessário introduzir na discussão será o da luta "contra a desconfiança progressiva na capacidade intelectual do aluno. A assumção de que a educabilidade da inteligência é possível abre amplas perspectivas à elaboração, intencional e sistemática, de estratégias metodológicas dirigidas ao desenvolvimento de competências do pensar" (Santos \& Praia 1992). O utra idéia que importa refere-se à necessidade de reagir contra a tendência para considerar o erro como evidente. Contudo, énecessário, neste contexto, considerá-lo como inevitável, discuti-lo, questionar as suas razões para que nós possamos aproximar da verdade possível, de momento. Este processo tem de ser partilhado pelos pares, não ignorando o papel do trabalho cooperativo e da "comunidade científica de alunos" que, em conjunto, procuram soluções para os problemas colocados e, mesmo, por eles equacionados.

Está em causa, pois, uma mudança no papel do aluno; este passa de receptor sobretudo de conteúdos científicos, a sujeito ativo na construção do seu próprio saber - de conhe cimento, quer conteudal quer processual. Isto exige-Ihe um esforço do ponto de vista conceptual, metodológico e atitudinal (Gil Perez 1993) mais consentâneo com a preconizada metodologia científica atual, que só é superável num ambiente escolar em que o professor caminha, intencionalmente, a par das dificuldades do aluno. Porém, não tem de seguir uma estratégia idêntica relativa ao pensar sobre as respostas a dar aos problemas. Ele deve procurar, sim, incentivar os alunos a consciencializarem as suas dificuldades, a pensar sobre o porquê delas, estando atento aos obstáculos que se colocam à aprendizagem, ou seja, deve ajudá-los e darIhes confiança para que se possam exprimir num clima de liberdade, sem perda do rigor intelectual. 


\section{A experiência científica}

$\mathrm{Na}$ prática científica moderna, é freqüentemente suposto que os fenômenos naturais são regidos por leis universais. Porém, no mundo natural esses fenômenos justapõem-se de maneira complexa. O ra, isto é incompatível com a elucidação das leis como regularidades empíricas e, também, indica porque é que as descrições dos dados observáveis são, em geral, bastante inapropriadas para construir conhecimentos básicos, a partir dos quais se elabora 0 conhecimento científico. Assim, a ciência requer a obtenção de dados com significado, sendo a intervenção experimental necessária como meio capaz de fazer ressaltar e trazer ao de cima, a informação epistemológica relevante e necessária ( Chalmers 1989).

D e uma forma geral, os empiristas e os indutivistas, para quem todo o conhecimento vem da experiência, tentam reduzir a experimentação a uma manipulação de variáveis. 0 investigador faz, antes de tudo, um inventário empírico de parâmetros susceptíveis de ter influência no fenômeno estudado para, em seguida, os fazer variar e, eventualmente, depois dos resultados obtidos, estabelecer uma lei que lhes dê sentido e coerência.

Porém, se o investigador supõe, para alguns parâmetros, uma importância particular, é porque possui uma hipótese articulada com o fenômeno em estudo. 0 investigador nunca experimenta ao acaso, mas sempre guiado por uma hipótese "lógica" que submete à experimentação.

"A experimentação, como prova física, tende a ser conduzida para o mundo real ou para "mundos possíveis", consoante a perspectiva é empirista ou racionalista .... Bachelard acentua, ironicamente, que enquanto o empirismo deduz leis de experiências, o racionalismo deduz experiências de leis" (Santos \& Praia 1992).

Para Popper, a experimentação científica não deve funcionar no sentido da confirmação positiva das hipóteses, mas no sentido da retificação dos erros contidos nessas hipóteses. Em todo o caso, nesta perspectiva, a experimentação exige uma grande e cuidada preparação teórica e técnica, precedida e integrada num projeto que a orienta. $D$ a reflexão dos resultados a que ela conduz pode, por sua vez, advir um outro saber a problematizar. "Já está ultrapassada a idéia da experiência como serva da teoria, sendo o seu propósito testar hipóteses... A experiência não é uma atividade monolítica, mas uma atividade que envolve muitas idéias, muitos tipos de compreensão, bem como muitas capacidades, tem vida própria" (H aching 1992).

Passamos a rever, com algum pormenor, as posições epistemológicas empirista e racionalista, para em seguida olhar melhor as suas implicações no trabalho escolar.

N uma perspectiva empirista, a experiência científica surge nos, quase sempre, como simples manipulação de variáveis, deduzindo leis (teorias) a partir dela própria ou da sua sistemática reprodução. Ela é determinante na obtenção de um conjunto de dados, que depois de interpretados levam a generalização (indução), também a evidência factual, produzida pela experiência, é o primeiro meio de estabelecer a credibilidade de uma teoria. A experiência científica fundamenta, pois, todo o conhecimento e só no final da(s) experiência(s) se faz questão, se toma em conta a(s) teoria(s). Ela como que está separada da própria teoria, para paradoxalmente a confirmar. A experiência científica valoriza, quase só a confirmação positiva do já previsto e obtido a partir dos dados observacionais, dados estes dotados de exterioridade. O s resultados da experiência surgem como esperados e mesmo óbvios.

É a experiência que põe à prova a teoria e não o inverso. M uitas vezes a constatação dos resultados experimentais levam a ignorar-se a hipótese que funciona como suposição transitória de valor epistemológico duvidoso, ou seja, a experiência é tida como algo separado da hipótese e não influencia os resultados daquela. 
0 que mais importa numa perspectiva empirista, olhada pelo lado didático, são os resultados finais independentemente dos processos da sua obtenção, ou seja, a experiência surge-nos não problemática, não relevando os aspectos mais complexos e difíceis da pesquisa, nem as condições teóricas e técnicas da sua produção. Também, muitas vezes, não se analisa e reflete no significado da experiência e tão só no que é previsível que aconteça.

N uma perspectiva racionalista, enquanto programa de investigação progressivo, a experiência científica deve ser guiada por uma hipótese, que procura funcionar, sobretudo, como tentativa da sua retificação e questionamento - ela interroga, problematiza - , conduzindo, muitas vezes, a outras hipóteses. Trata-se de um diálogo entre hipóteses/teorias e a própria experimentação, diálogo nem sempre simples, já que, também aqui, o confronto entre 0 teórico (o idealizado) e a prática (o realizado) se interligam. Reside aqui, pensamos, uma das riquezas heurísticas da experimentação. Se a hipótese intervém ativamente nas explicações que os resultados da experiência sugerem, a teoria tem um papel primordial na avaliação dos resultados obtidos.

A experiência científica é orientada e mesmo valorizada pelo enquadramento teórico do sujeito, que em diálogo com ela, a questiona, a submete a um interrogatório, de respostas não definitivas. A experiência enquadra-se num método pouco estruturado, que comporta uma diversidade de caminhos, ajustando-se ao contexto e à própria situação investigativa. O s seus resultados são lidos como elementos (possíveis) de construção de modelos interpretativos do mundo e não cópias (e muito menos fiéis) do real.

Como poderíamos afirmar que a experimentação científica encerra múltiplos fatores não apenas tecnológicos, mas histórico-culturais, ético-morais, políticos, religiosos ... que condicionam e, em muitos casos na atualidade, (re)orientam e (re)centram a atividade de pesquisa, como construção e produção social do conhecimento científico, como empreendimento humano que toma opções e tomadas de posição não neutrais, mas carregadas de val ores. A comunidade científica tem, também, um papel primordial que importa não esquecer. A expe riência enquadra-se num processo não de saber-fazer, mas de reflexão sistemático, de criatividade e mesmo de invenção.

A transposição didática, realizada com cautela para não cairmos em simplismos fáceis, deve traduzir-se em sugestões de propostas de atividades de ensino-aprendizagem, que val orizem o papel do aluno no sentido primeiro de o confrontar com as suas situações de erro para posteriormente as vir a retificar. D o ponto de vista didático, ao sujeitarmos a experiência científica a uma tentativa de questionamento estamos convidando os al unos a desenvolveremse cognitivamente, num confronto de idéias com os seus pares, em que o resultado não só não está de antemão conseguido, como tem que ser sempre olhado à luz dos seus quadros interpretativos4.

No sentido de assinalarmos incidências da reflexão epistemológica da ciência no trabalho experimental escolar, C achapuz (1992) diz-nos que "uma sala de aula não é um laboratório de investigação, pelo que as estratégias a adotar têm que ter legitimidade quer filosófica quer pedagógica. Há pois que harmonizar estas duas dimensões".

Por outro lado, Hodson (1990) considera que o trabalho experimental tal como é conduzido em muitas escolas é de concepção pobre, confuso e não produtivo. Para ele, muitos professores acreditam que 0 trabalho experimental ensina os estudantes sobre 0 que é a

\footnotetext{
${ }^{4}$ Apesar da perspectiva epistemológica subjacente à questão da experimentação ser algo marcado por uma visão popperiana, entendemos que numa situação de testagem, em ambi ente escolar, ela afigura-senos como uma alternativa útil aos professores. Tal não significa que os autores do artigo partilhem, de todo, a perspectiva popperiana - ver, nomeadamente, Gil Pérez et al., 2001.
} 
ciência e a sua metodologia. T êm sido uns entusiastas ao acreditar que o caminho para aprender ciência, os seus métodos e processos é "descobrir aprendendo" ou "aprender fazendo". Para aquele investigador em Educação em Ciência os professores usam o trabal ho experimental sem uma adequada reflexão, ou seja, mantêm o mito de que ele é a solução para os proble mas de aprendizagem em ambiente laboratorial. Esta visão distorcida baseia-se em pressupostos epistemológicos, psicológicos e didácticos que têm vindo a ser, progressivamente, postos em causa, ou seja, é uma visão que corresponde a um programa em regressão epistemológica.

$M$ uitos dos objetivos que se estabelecem para o trabalho experimental escolar e que os professores quase sempre enunciam referem-se, entre outros, ao seu forte sentido motivador, bem como ao desenvolvimento de atitudes científicas tais como a objetividade, a ausência de juízos de valor, a abertura de espírito. 0 trabalho experimental é, pois, orientado para fomentar a aprendizagem de conceitos e métodos da ciência, queH odson (1990) não só questiona, como volta a perguntar qual o significado do trabal ho experimental, sobretudo no que diz respeito ao aprender ciências na sala de aula de acordo com as perspectivas epistemológicas atuais. 0 autor vai ao ponto de referir que "muito do que se faz está mal concebido e não apresenta qualquer valor educacional, urge redefinir e reorientar a noção que os professores têm sobre o trabalho prático.

$N$ uma perspectiva inadequada da experiência científica real izada na sala de aula, não se analisa e reflete nos resultados, à luz do quadro teórico e das hipóteses enunciadas, mas ape nas se constata o que era mais do que previsível que acontecesse - a experiência realizou-se para dar determinado resultado já esperado e conhecido de antemão. $\mathrm{Na}$ perspectiva que vimos falando, de forte pendor empirista, a experiência surge, quase sempre, como algo episódico, ligada a uma visão heróica do cientista; ignora, pois, os contextos sociais, tecnológicos e culturais da construção e produção científica, que o professor tem de conhecer e não se pode alhear, deixando à margem das suas aulas. Caso contrário, a experiência científica escolar toma o sentido do fazer, sem saber por que e para quê. Estamos, neste caso, a considerar a ciência numa lógica que está fora da própria história do pensamento as idéias, desvalorizando o sentido da própria luta por idéias mais verdadeiras, isto é, mais explicativas para os fenômenos naturais.

Entretanto, Tamir (1977) distingue dois tipos de trabalho experimental: os de verificação e os de investigação. No primeiro caso é o professor que identifica o problema, que relaciona o trabal ho com outros anteriores, que conduz as demonstrações (fora de um contexto de problematização) e dá instruções diretas - tipo receita.

Q uanto ao segundo tipo de trabalho experimental, tipo investigativo, deixam-se al gumas notas sobre o sentido com que a experimentação deve ser encarada na sala de aula:

i) deve ser um meio para explorar as idéias dos alunos e desenvolver a sua compreensão conceptual;

ii) deve ser sustentado por uma base teórica prévia informadora e orientadora da análise dos resultados;

iii) deve ser delineada pelos alunos para possibilitar um maior controle sobre a sua própria aprendizagem, sobre as suas dificuldades e de refletir sobre o porquê delas, para as ultrapassar.

N o seguimento desta orientação o trabalho experimental deve ser redefinido, tendo em atenção novos objetivos do ensino das ciências. N este sentido, H odson $(1992,1993,1994)$ descreveu como objetivos centrais: 
1. Aprendizagem das ciências: como a aquisição e o desenvolvimento de conhecimentos teóricos (conteúdos das ciências).

2. Aprendizagem sobre a natureza das ciências: o desenvolvimento da natureza e dos métodos da ciência, tomando consciência das interações complexas entre ciência e sociedade.

3. A prática da ciência: desenvolvimento dos conhecimentos técnicos, éticos, entre outros, sobre a investigação científica e a resolução de problemas.

$\mathrm{N}$ uma outra linha de pensamento, interessa sublinhar que em muitas situações de ensino 0 estudo de casos históricos, incluindo a eventual exploração de "experiências cruciais", quando está em jogo o conceito de testagem, pode ser útil didaticamente. A experimentação, neste sentido, de forte pendor racionalista crítico de raiz popperiana, pode ser usada para uma possível escolha de teorias em competição. 0 desenvolvimento intergrupal e intragrupal, pode, no quadro de uma sempre prudente analogia com a comunidade científica, ajudar a simular aspectos sociológicos, particularmente interessantes. A crítica, a argumentação e 0 consenso dos pares constituem elementos de racional idade científica que importa desenvolver conjuntamente - alunos e professores - partilhando e vivendo dificuldades inerentes à própria prática científica. D esta maneira, tal exercício escolar permite uma aprendizagem efetiva, significativa e com sentido de cidadania.

Importa sublinhar que uma ou duas experiências não dão resposta definitiva ao problema, nem abalam uma teoria que está a ser discutida. 0 confronto é mais vasto, tem incidências não só em nível lógico como também em nível sociológico. 0 que pode estar em causa é, sobretudo, a questão da hipótese que a experiência põe à prova: a confirmação positiva ou negativa. Em síntese: a relação entre a experimentação e a teoria é bem mais complexa do que muitos professores pensam e é, de certo, também por isso, que raramente ela é equacionada e pensada, desta forma, na sala de aula. H á que considerar outras possíveis alternativas mais enriquecedoras como sejam contra-exemplos, experiências intencionalmente orientadas para levar a resultados não esperados e referência a resultados que vêm da literatura.

Por outro lado, o problema da indução está presente em muitas das abordagens que os professores fazem, levando a generalizações fáceis e demasiado simplistas. No $\mathrm{V}$ epistemológico de Gowin, instrumento didático de grande utilidade, é quase sempre considerado apenas o lado esquerdo (conceptual), não estando presentes as suas relações com o lado direito (metodológico). Entretanto, fazem-se apressadas generalizações a partir de uma ou duas experiências, das comumente chamadas "experiências para ver". Por outro lado, a repetibilidade não é, como muitos professores pensam, uma propriedade do conhecimento científico. Esta abordagem já não é hoje aceita, mesmo à luz de pressupostos epistemológicos de natureza e de sentido inequivocamente positivista.

0 que nos parece de sublinhar é, pois, a necessária mudança de atitude dos professores, no sentido de ultrapassarem a aceitação fácil de um empirismo clássico e ingênuo, concebendo a ciência como uma simples descoberta, quer pela observação neutral, quer pela confirmação experimental escolar positiva. Importa que os professores compreendam e se consciencializem da importância do elemento cognitivo, da discussão argumentativa, que atribuam ao estudo e à reflexão um espaço indispensável para compreender as dificuldades e a complexidade que se reveste um tal processo de construção da ciência. $N$ ão se pode, entretanto, ignorar o papel do sujeito na construção do conhecimento, nomeadamente através do confronto com os conceitos e teorias aceitas em ciência. 
Conforme referem Gil Pérez (1993) e Beviá (1994), torna-se necessário planificar a aprendizagem a partir do tratamento de situações problemáticas abertas, susceptíveis de interessar os alunos a desenvolver um plano experimental coerente, que não seja indicado pelo professor, mas proposto por um grupo de alunos. Essas atividades, como refere Beviá (1994), podem ser guiadas pelo docente, possibilitando aos alunos a percepção da variedade de processos implicados na atividade científica. D este modo estará criado nos grupos de trabalho um clima propício para fazer emergir, entre outras, as interrogações, as dúvidas, as incoerências, as deficiências, a consciência das limitações teóricas,... gerando as vivências que permitem aos alunos refletir, conjuntamente, sobre as características do trabalho científico.

M aria de Sousa (1992), investigadora em ciência, ao falar-nos das características do trabalho científico, em particular da experiência científica refere que ele se situa em "uma esfera muito alargada e dinâmica, mantida em movimento pela interação contínua entre conjectura e refutação". No seu artigo intitulado Procedimentos experimentais. sobre cozinheiros chefes e cientistas, distingue três elementos principais: o consenso dos pares, o desafio dos dogmas e a combinação única entre a arrogância e a humildade. Trata-se, assim, também de valores e atitudes inerentes ao processo científico escolar, a uma aprendizagem capaz de mudar as próprias representações de ciência.

\section{A concluir}

M uito do que acabamos de referir traduz-se em dificuldades e fatores, susceptíveis de determinar uma atuação cuidadosa do professor, exigindo-lhe uma aprofundada formação científica que não passa unicamente, longe disso, por possuir uns tantos conhecimentos adquiridos na formação inicial. A transposição didática, feita de reflexão e consubstanciada na própia ação didática, exige uma formação contínua que segue um percurso de desenvolvimento pessoal e profissional exigentes.

U ma chamada de atenção para tornar claro que o professor tem de ter cuidados muito particulares com o processo de aprendizagem e, em particular, com as atividades que promove. Estas devem desenvolver-se na "zona de desenvolvimento próximo", o mesmo é dizer que tais tarefas devem ser um desafio, porém, com um grau de dificuldade susceptível de se constituirem em incentivo e não de fonte de desânimo, desmotivação e de impossibilidade de resolução.

Referir ainda que a simplicidade com que os problemas e os fenômenos são apresentados (atente-se ao nível etário) obrigam o professor a retomá-los mais adiante e, sempre que possível, a ligá-los a outros para os articular de forma a que o currículo em espiral seja possível. A conceptualização, a que não é al heio o ritmo e o tempo de aprendizagem, é mais bem conseguida e a compreensão das idéias estruturantes torna-se o fio condutor das propostas de ação didática do professor. As experiências de aprendizagem que o professor promove são meios que devem ser considerados como instrumentos para melhorar a explicação que se dá para os fenômenos e não podem ser consideradas como fins em si mesmas. Servem pelas interrogações que suscitam e pela busca de explicações mais verdadeiras, porque argumentativamente mais apoiadas.

Por fim, chama-se a atenção para a tentação de uma excessiva motivação para experimentar e que o professor, bem intencionadamente, introduz na aula de laboratório. A espectacularidade dos fenômenos, aliada à sua apresentação, nomeadamente, quer através de registros, vídeo, quer outros, ainda que sejam fatores positivos, podem não ajudar a potenciar a aprendizagem desejada. Pode mesmo invertêla e tornála sociologicamente perversa, ou seja, pode desvalorizar razões epistemológicas e didáticas que deviam ser orientadoras e determinantes da ação, 
em favor de razões de pedagogia geral, em particular motivacionais que fazem perder o sentido das primeiras.

Está, em causa, uma formação de professores que se quer "completa", isto é, que articule epistemologia e didática e que releve conjuntamente teoria e prática, como uma unidade intrínseca. Só assim seremos capazes de gerar, tentativamente, materiais didáticos, enquanto recursos fundamentais para o exercício de práticas de sala de aula mais consentâneas com o que se preconiza numa perspectiva de ensino por pesquisa (C achapuz, Praia \& Jorge, 2001).

Trata-se, coerentemente, de usar a formação como um processo de pesquisa efetuando investigação com os professores, com vista a que tal produção de saberes seja reinvestida na inovação para que esta, persistentemente, se venha a transformar em mudança.

\section{Referências bibliográficas}

BEVIÁ, J. L. Los trabal os prácticos de Ciencias $N$ aturales como actividad reflexiva, crítica y creativa. In: Alambique. Didáctica de las Ciencias Experimentales, 2, 47-56, 1994.

CACH APUZ, A. F., Filosofia da Ciência e Ensino da Q uímica: repensar o papel do trabaIho experimental. Congresso Las D idácticas Específicas en la Formación del Profesorado, Actas... Eds. M ontero M esa e Vaz Jeremias, Tomo II, v. 1, 357-363, Santiago de Compostela, 1992.

CACH APUZ, A. F., O Ensino das C iências para a excelência da aprendizagem. In: N ovas M etodologias em Educação, Ed. A. D ias de C arvalho (O rg.). p. 349-385. Porto: Porto Editora, 1995.

CACH APUZ, A., PRAIA, J. \& JORGE, M. Perspectivas de Ensino. In: Formação de Professores de Ciências, nำ1, A. Cachapuz (O rg.), Centro de Estudos de Educação em Ciência. Porto, 2001.

CH ALM ERS, A. F. Q ué es esa cosa llamada ciencia? (E. P. Sedeño y P. L. M añez, trads.). $M$ adrid: Siglo Veintiuno de España, 1989.

EN CIC LO PÉD IA EIN AU DI, M étodo-Teoria, v. 21. Lisboa: Imprensa N acional, C asa da M oeda, 1992.

GIL PÉREZ, D ., Contribución de la historia y de la filosofía de las ciencias al desarrollo de un modelo de enseñanza/aprendizaje como investigación. Enseñanza de las Ciencias, v. 11, n. 2, p. 197-212, 1993.

GIL PÉREZ; D., MONTORO, I. F., ALÍS; J. C., CACH APUZ, A. \& PRAIA; J. Por uma imagem não deformada do trabalho científico. Ciência \& Educação, v. 7, n. 2, p. 125-153, 2001.

H ACKIN G; I. Refazer o mundo. In: A Ciência como Cultura, 103-118. Lisboa: Imprensa N acional Casa da M oeda, 1992.

H O DSO N, D .. Filosofia de da Ciência y Educación Científica. In: Constructivismo y Enseñanza de las Ciencias, R. Porlán, J. E. Garcia \& P. C añal (Compil.), 5-21. Sevilha: Diada Editoras, 1988.

HO DSO N, D. A critical look at pratical work in school Science. School Science Review, v. 70, n. 256. p. 33-40, 1990. 
HODSON, D.Redefining and reorienting pratical work in school science. School Science Review, v. 73, n. 264: 65-78, 1992.

HODSO N , D., Rethinking old ways: towards a more critical approach to pratical work in School Science. Studies in Science Education, v. 22, n. 85, p. 142, 1993.

HOD SO N , D. H acia un enfoque más crítico del trabajo de laboratorio. Enseñanza de las Ciencias, v. 12, n. 3, p. 299-313, 1994.

MASKILL, R. \& WALLIS, K. G. Scientific thinking in the classroom. School Science Review, v. 63, n. 224, p. 551-554, 1982.

SAN TOS, M . E. \& PRAIA, J. F. Percurso de mudança na D idáctica das Ciências. Sua fundamentação epistemológica. In: Ensino das Ciências e F ormação de Professores. 7-34. Projecto M UTARE / Universidade de Aveiro, 1992.

SO USA, M. Procedimentos experimentais: sobre cozinheiros-chefes e cientistas. In: Ciência como Cultura, F. Gil (O rg.). A. 91-102. Lisboa: Imprensa N acional - C asa da M oeda., 1992. (Estudos Gerais, Série Universitária).

TAM IR, P. H ow are the laboratories used ? Journal of Research in Science Teaching, v. 14, n. 4, p. 311-316, 1977.

\section{Artigo recebido em março de 2002 e selecionado para publicação em novembro de 2002.}

